\title{
The Introduction of Innovative Services in a State Owned Airline: A Case Study of an IT Migration Project
}

\author{
Konstantinos N. Malagas', Kyriakos I. Kourousis², Glenn Baxter ${ }^{3}$, Nikitas Nikitakos ${ }^{4}$, Stefanos Gritzalis ${ }^{5}$
}

\begin{abstract}
This study critically examines the transition process followed by a state-owned airline in a major IT migration project (introduction of novel electronic services). The change management process proposed by Kotter (1995) is examined in relation to the different phases identified, based on an interview based qualitative research. Focusing on the project team leaders a set of results is identified / determined, which provides significant insight into the key factors, deficiencies and outcomes of the project, with reference to the characteristics of a state-owned company. Further elaboration of the proposed methodology is deemed to be applicable in the identification of the weak and strong points of similar change projects.
\end{abstract}

Keywords: change management; organizational change; e-ticket; e-services; airlines.

\footnotetext{
1,5 Department of Information and Communication Systems Engineering, University of the Aegean, Karlovassi, Samos 83200, Greece. E-mail: 'kmalagas@aegean.gr.

${ }^{2,3}$ School of Aerospace, Mechanical and Manufacturing Engineering, RMIT University, Melbourne, GPO Box 2476,Victoria 300 I, Australia. ${ }^{4}$ Department of Shipping Trade and Transport, University of the Aegean, Korai 2a, Chios 82100, Greece.
} 


\section{Introduction}

Technological innovation is the commonest change the aviation industry makes in an effort to meet the demands of a competitive market which includes low-cost, no frills carriers, and the e-commerce (Doganis, 200I). Companies prepared to adopt and innovate can take advantage of a rapidly changing technology which offers new services to meet every demand (Goffee and Jones, 2003). Information Technology (IT) assists aviation industry to improve its customer services and respond to contemporary challenges. Thus, IT reinforces the development of new relationships between all the participants in the aviation industry such as airlines, passengers, airport authorities, operators, ground handlers and aircraft (Violante, 2008).

In addition, the use of IT has assisted airlines to reduce their operating costs, to produce new revenues and to improve customers' service quality. During the past decade, two major developments in IT have been identified as those with the greatest impact in the aviation industry; that is the introduction of e-Ticket and e-Commerce (Violante, 2008). These electronic services have long been considered to be the most promising technological innovation tools offered to the commercial airlines business. For example, the traditional paper airline ticket was very expensive to administer, costing an estimated 10 US Dollars per coupon to print, distribute and process (Doganis, 200I). In addition, the convoluted process of accounting for flown versus ticketed revenue delays an airlines' ability to account for revenue until at least 10 - 15 days after the month of travel and sometimes longer undermining cash-flow and providing delayed management information. As a result, the world's airlines have developed the e-Ticket; which is a fully paperless ticketing system.

In 1994, United Airlines was the first airline to issue electronic tickets. However, a decade later only 20 per cent of all airline tickets were electronic. The industry was not taking advantage of an opportunity to reduce and save costs and make travel for passengers easier. In June 2004, IATA established an industry target of 100 per cent e-ticketing by 2008. On I June 2008 , the world airline industry moved to 100 per cent electronic ticketing and the requirement for a paper ticket became a thing of the past. The use of e-tickets has resulted in a substantial cost saving for the industry of around US\$ 3 billion per year. In addition, the e-Ticket is also more convenient for passengers who no longer have to be concerned about losing tickets and they can also make changes to itineraries more easily (International Air Transport Association 20l la). Nevertheless, the most important aspect of the e-ticketing product is that it allows airlines to sell via the Internet much more easily and has allowed substantial increases in this cost effective sales channel (Be- lobaba et al. 2010). In their effort to reduce cost and at the same time improve their customer relationships, airlines will drive increasing amount of business to their direct channels, with particular emphasis on the website. Increased e-Ticket functionality and customer acceptance combined with frequent flyer programs and price incentives is likely to support accelerated growth in airline web sites and airline backed e-agencies.

IT services require changes within the aviation industry, which in turn airlines should make the necessary changes so as to respond to the new requirements and support these new services. In most of the cases airlines outsource these services to certain providers in the global market. Firms use outsource solutions in order to introduce advanced services particularly for IT projects because they may not have sufficient in-house know-how or/and expertise, or they may be under time or budget pressures (Gantz, 1990; Sengupta and Zviran, 1997; Bathelemy, 200 I).Although the e-Ticket played a pivotal role for the adoption of new technologies, e-Ticket alone is not an issue of product differentiation and a competitive tool (McDonald, 2009b). However, airlines do not operate autonomously, and they must interact with distributors and service providers and, therefore, follow the current industry standards and trends in order to differentiate and outshine faster (McDonald, 2009a). In addition, airlines have benefited synergies that providers can achieve through hosting a large number of airlines (e.g. the SabreSonic customer service system hosts 100 airlines), which means that they can offer advanced and cost-efficient services to the customers.

IT migration projects, such as the case of electronic services in an airline, need be adapted to both the company's organizational structure and culture; thus the challenge is to design and apply a series of changes that will allow for a successful outcome. Hence, the selection of the electronic solution must fit adequately to the company, in terms of its technology readiness and cultural profile (McLaughin, 2009). Another critical factor is, in fact, the change management process itself. A solid, yet flexible, process of designing, supporting, communicating, implementing and promoting the changes that have to be made is of vital importance for the success of these projects. One of the most common phased organizational change methodologies is examined under the prism of a state owned airline electronic services migration project.

\section{The Phases of Organizational Change}

Organizational change is one of the most explored subjects, and a large number of articles and papers deal with this concept (Washington and Hacker, 2005). During the last 15 years, no material modification has taken place regarding

ISSN: 07 I8-2724. (http://www.jotmi.org)

Journal of Technology Management \& Innovation (c) Universidad Alberto Hurtado, Facultad de Economía y Negocios. 
the concepts to organizational change (Boshoff, 2005), but we should keep learning more about organizational change (Longenecker and Fink, 200I). Alvesson and Sveningsson (2008) stressed that the continuous organizational change is the normal situation and no stability. The reasons that an organization pursue change can happen for external (face of competition, the appearance of new technologies, loss of customers, regulation changes, etc) or/and internal (bad staff behaviors, problematic organizational structure, introduction of new products and services, new people in key positions, lack of orientation to technology, introvert organizations, low confidence to management etc) reasons (Smith 2005; Alvesson and Sveningsson 2008).

Organizational change has a direct impact on people's work life, which in most cases leads to the development of a mixed behavior in terms of their willingness to participate in the process. It is, therefore, important to identify and overcome these drawback forces in order for any change to succeed. Regarding organizational change, in order to achieve success it is thought that certain steps (n-steps) should be followed (using standard rules and the appropriate values) (Kotter, 1995). However, there is a criticism for this opinion because this does not include the unexpectable that characterizes the change process (Alvesson and Sveningsson, 2008).

A successful transition scheme may take the form of a phased approach, split in eight independent, in terms of time requirements, stages (Kotter, 1995). This approach is particularly helpful when examining large scale projects in companies because it is considered to be a comprehensive theory that takes into account the various parameters involved in change, such as the time, the necessary preparation, the strategies, as well as the human factors (e.g. people's motivation, change of behavior, etc).

According to Kotter's theoretical model the phases an organization should go through are to manage the introduction of innovation are summarized as following:

I. Establishing a sense of urgency

2. Forming a powerful guiding coalition

3. Creating a vision

4. Communicating the vision

5. Empowering others to act on the vision

6. Planning for and creating short-term wins

7. Consolidating improvements and producing still more change

8. Institutionalizing new approaches

The different phases and the associated implications to change management are analyzed briefly in the following sections.

\section{Establishing a sense of urgency}

The emphasis in this phase, which is considered to be the most difficult, is to create a sense of urgency to the company's staff and more particularly to the innovation developers and managers. The introduction of change and innovation starts when individuals and/or groups in a company start examining the critical performance indices of the company, such as its competitiveness, financial performance and position in the market, in conjunction with the potential benefits of technological innovation. Once this critical evaluation takes place the company can get a very clear view of the existing weak points, and this, in turn, acts as a means of alert for the low, mid or high level management staff. As explicitly noted by Kotter, there are not very many chances for a company to succeed in change; unless people feel the urgency to act upon issues or problems. In fact, it is dull situation of a company that may act as a fuel for emergency actions and maneuvers, even though there is limited space for that, due to the criticality of the situation. Although the best approach to implement the necessary changes is to move in smaller rather than large steps (Singh and Singh, 20I2), usually changes have to be done within very strict time and budget limits (Steinburg, 1992; Bovey and Hede, 200I). Therefore, this fact is more to cause high levels of stress and speculation to an organization's management, which eventually demands skillful and multilevel handling and control.

\section{Forming a powerful guiding coalition}

The development of a project team with strong managerial skills, excellent subject knowledge and commitment to change is essential for any organizational change, most identifiably for large scale projects. This project team guides the rest of the company's personnel, which in effect requires increased authority for functioning and sometimes surpassing the hierarchy, the norms, the expectations and the protocol of the company in order to have a fast and efficient decision making process in place. Thus, part of the team's power has to derive from the provision of the necessary capacity and resources by the company's top management (Simpson and Cacioppe, 200 I). It is also vital, for the success of the project, thus team to have strong collaborative skills and spirit, as well as to be able to inspire and engage the staff directly or indirectly involved in the project.

\section{Creating a vision}

The development of a strong and vivid vision is important to act as a guide to the effort for change in the organization. Consequently, strategies for the realization of this vision need to be planned and implemented and moreover commitment to a clearly shared vision is an important element which contributes not only to the implementation of change,

ISSN: 07I 8-2724. (http://www.jotmi.org)

Journal of Technology Management \& Innovation (c) Universidad Alberto Hurtado, Facultad de Economía y Negocios. 
but also to the transformation of a company's culture (Simpson and Cacioppe, 200I). It is, in fact, the commitment of the senior executive officers, which assures that the company is willing to support the project by providing the necessary human (technical expertise, time, etc.) and material resources (money, infrastructure, technical means, etc.).

\section{Communicating the vision}

Transmission of the vision to the staff constitutes clear and effective communication of the scheduled, as well as the actual work done within the project. This communication should clarify not only the general aims or the specific targets of the project, but also the expectations from staff, the impact of this change, the ways they are going to achieve what the vision describes, as well as update and feedback on the current status. It is also of particular importance that the project team demonstrates behaviors and models the way things should work in order to succeed. Modeling of new behaviors and the exploitation of new knowledge produced during the course of the project is a ground rule important for every transformation to succeed (Simpson and Cacioppe, 200 I). Moreover, if drastic changes are necessary to take place, old hierarchies, it becomes apparent that the way business was done in the past (e.g. decision making procedures, management structure, work posts, etc.) becomes obsolete and, therefore, not consistent with the changes (Steinburg, 1992; Bovey and Hede, 200I).

\section{Empowering others to act on the vision}

The implementation of strategies requires the assignment of additional responsibilities to a growing project management team. This involves not only typically allocating duties to people, but also encouraging them to take on extra responsibilities, initiatives and risks. In this phase, the seeding of other departments and groups is attempted, which aims to spread the learning an innovation demands throughout the organization (Strong et al., 2008). This is complemented by the removal of any obstacles, related either to the company's structure and protocol or to the particular working attitudes of the employees. A strategy that can be facilitated towards this is to identify and engage the people who have a positive attitude and do pursue the change and further on equip them with the necessary authority to restructure, implement and enforce the changes in the organization.

\section{Planning for and creating short-term wins}

Short-term targets and successes need to be planned and incorporated in a step-wise scheme, not only as part of the strategic planning of the project, but also as a rewarding process for the staff involved in the project. These actionable first steps are drivers for further success and are expected to increase the level of situational awareness, work satisfaction and morale of the staff (Simpson and Cacioppe, 200I). The short-term targets/wins strategy can also be considered to be the appropriate solution to address the change management problems in more bureaucratic structured organizations, due to the fact that it could reduce the complexity of a large scale project. People, can be more efficient, effective and productive as soon as they are convinced that their work has a direct impact on the project.

\section{Consolidating improvements and producing still more change}

Stabilization of the improvements along with the development of further changes can be facilitated through increased credibility, engaging the right people and invigorating the process with new projects, themes and change agents (Kotter, 1995). As part of this process learning communities can be developed, in which different groups can learn from each other. Rather than changing everything in once, a company might use this idea for gradually disseminating new knowledge and behaviors. The best learning in organizations happens when organizations learn from their own successes and failures (lessons learned) (Conner et al., 1992).An important aspect in the continuous phase is to establish a motivation system, which is necessary to awards employees, as well as to disseminate information about the benefits yielded by the introduction of change. This can in turn increase the level of enthusiasm among the employees, which is vital for the ongoing success of the change process.

\section{Institutionalizing new approaches}

The final phase identified is the need for a change in the company culture and behavior so that consolidation and further development continue to take place even after the end of the project. This can be regarded as the establishment of an organizational culture which complies with and supports the stabilization of improvements, as well as a continuous evolution process, allowing for further improvement. It is, in fact, organizational culture that not only affects performance in a direct manner, but it adds up quality to the customer services offered by a company (Lee and Yu, 2004; Cummings and Worley, 2008; Kotter and Heskett, 20II). It has been also recognized that the active participation of all personnel involved in the process of change is necessary in order for this process to reach success, both in short and longrun (Jackson, 2000; Kennedy, 2000). Management changes should not only affect the way business is run, but also influence the way people think, act and interact with each other. Problematic behaviors, with respect to alignment with the business strategy, arise when people disregard the changes. This happens because they are not capable to comprehend and adjust to the changes. In this case, the rate of resilience

ISSN: 07 I8-2724. (http://www.jotmi.org)

Journal of Technology Management \& Innovation (c) Universidad Alberto Hurtado, Facultad de Economía y Negocios. 
among employees should increase so that higher levels of change are accepted without people being distracted by the difficulties and obstacles met (Steinburg, 1992; Kotter 1995; Coutu 2002).

\section{Case Study:Transition to an e-ticket System in a State-owned Passenger Airline}

\section{Case Description}

The case studied included a state-owned airline which experienced an urgent situation where it had to undergo a series of organizational changes in a very short period, in order to stay in business. In particular, this company had to implement the e-ticket service, according to IATA's instructions and took the decision to introduce a Passenger Service System and take up the related costs in order to become more competitive and more attractive to passengers, as well as potential private investors. The company's management took the decision to introduce the e-ticket service, just a year before the deadline for the e-ticket implementation imposed by IATA. The new Passenger Service System included the implementation and replacement of the reservation, airports departure control, internet sales, frequent flyer, and the revenue management systems. At that time, the project had been identified as very crucial for the company's viability, in terms of the associated risk to introduce a series of major changes in a very short period, and just a year before the expiration of the IATA's deadline for paper tickets issuing. An additional factor that contributed to that had to do with the decision to outsource the development of these services, which contradicted the previous practice (in-house development of software and systems, by the company's IT department). This migration project was completed in almost five months (from management's decision to the full deployment of the electronic services), a performance that had been considered by the industry officials (IATA) as a major accomplishment at that time.

However, the company did confront some serious problems at that time, which were related to the bureaucratic structure, the over-centralized management and the continuous intervention of the Government, typical symptoms of the 'distressed state airline syndrome' of which the airline suffered (Doganis, 200I). Apart from the need for innovation which drove the project into the success, it is important to identify the key factors that enabled the successful migration, and question whether if this is the result of well planning and strategic management, based on the change management scheme proposed by Kotter.

\section{Research and Analysis Methodology}

The study involved interviewing the employees directly involved in the implementation of the change process and the new services in the company, in order to be able to conduct an analysis of the experience of key-personnel with respect to the different phases as outlined in section 3. In particular, the sample group consisted of the company's Chief Executive Officer (CEO), General Directors and members of the project team. A limited sampling logic was applied in order to focus on the staff that experienced intimately the migration process to the new electronic services. This group of people was responsible for the preparation and implementation of the project, as well as for the training and education of the rest of the associated with the project airline's staff. Moreover, this limitation was necessary due to the fact that in case more employees of the company were studied, then the uncertainty of the results would probably be increased due to the expected diversity of responses (sharing of the same view, situational awareness, etc.).

The research followed a qualitative pattern, in which validity is replaced by the concept of transferability, in terms of the ability of the research outputs capability to transfer situations with similar parameters, populations and characteristics. This research has a significant degree of transferability, which is supported through careful transcription, thorough and systematic analysis of the data and information about the theoretical context which was used to generate and analyze the data. The data were collected through a semistructured interview scheme (narrative) because the aim was to discover the different ways individuals experienced the various phases of the migration project, as well as the way they realized their role and contribution within the particular context and situations. As narrative is experiential, it can provide a description of tacitly held personal knowledge without abandoning the particular, the contextual, and the complex (Conle, 2000).

The interview questions were designed upon the basis of the change management phases proposed by Kotter while additional questions were added to seek for the employees view and feelings about the outsourcing choice (decision, performance, etc.). The interview questions were piloted with a set of participants, which allowed for some revisions and improvements for the final set of the interviewed staff. Based on this research methodology, the responses received by the interviewed staff can be considered as snapshots of their understanding at the particular time-space domain while the magnitude of influence from the socio-cultural milieux is not completely clear (Conle, 2000). It is also noted that the interpretation of the events that took place in the change process are culturally bound and, therefore, the understanding of people differs for the different groups in the

ISSN: 07I 8-2724. (http://www.jotmi.org)

Journal of Technology Management \& Innovation (c) Universidad Alberto Hurtado, Facultad de Economía y Negocios. 
same company. However, narrative can reveal how people experience change and which factors influence situations and make particular events possible.

The research faced the dilemma of anonymity as there are some particular details that could identify the participants of this research (small group of people, very particular responsibilities and tasks in the project, etc.). Nevertheless, all names have been eliminated to establish an acceptable level of privacy. In addition, emphasis was given to handling the information in a discrete and responsible way.

The analysis of the data went through three phases; the interview transcription, the analysis and the interpretation phase. In particular, regarding the second phase, emphasis was given on the identification of key words, essential features, experiences as well as their interrelations while, in the third phase, the aim was to link the case of each participant with larger issues and the theory. The challenges in the analysis and interpretation phases were to identify: the relevance of negative or positive answers to the clarity of the questions and the particular circumstances which defined the participants' experiences in the project. The research question raised was to identify and validate the occurrence of these particular eight phases, as well as to assess the extent of variation, due to the specific circumstances and environment of the company. This kind of interpretation requires hermeneutic work, which aimed to introduce new aspects to the original narrative that exceeded the mere description (Bennetts, 2002).

\section{Discussion of the Results}

The research results provide evidence that the introduction of the new e-services in the case study state-owned airline did follow in general the change management phases proposed by Kotter (1995). However, there are some features which can be identified in the process (as analyzed in the following sections). Table I summarizes the same results and provides the basis for the validation and observed deviations.

\section{Establishing a sense of urgency}

The participants of the study confirmed the existence of the sense of urgency among the staff involved in this project. In particular, the fast and accurate dissemination of all necessary information led to the establishment of the necessary level of understanding among staff, both in terms of urgency and significance of the project. However, as a significant number of the respondents highlighted, this sense of urgency came from an external alert which, in fact, was IATA's resolution about the introduction of the e-ticket. The interviewees also commented on the company's hesitation to follow current industry practices, as well as on the slow developmental paces (caused by the bureaucratic management structure and practices). This in turn, put the company in a critical situation, allowing minimal or zero maneuverability and leading to a series of knock-on effects, which influenced the other phases of the change process.

\section{Forming a powerful guiding coalition}

The formation of a highly skilled project team was apparent. Also, the respondents identified that this team worked in a rather independent mode, having enhanced operational flexibility and efficiency. Nevertheless, some performance deficiencies occurred from restrictions imposed by the company's protocol, in terms of decisions that had to be made by the top management. Since the top management was not part of the project team, this led to delays (nonproductive time) in the course of the project.

\section{Creating a vision}

All of the respondents recognized the creation a vision for this project, which was the introduction of the new eservices in a constrained timeframe (imposed by the IATA requirements). This was in direct relation to the company's viability, as well as with the necessity to improve the company's market profile. In contrast, the strategies developed to lead the successful realization of this vision were not clearly identifiable, based on the responses received from the team members. This, in fact, brings out the issue of inconsistent communication between the different parties involved in this project (management, project team and associated staff).

\section{Communicating the vision}

The interview results showed that the company has used a variety of means and ways to communicate and disseminate the information relevant to the project aims and objectives, as well as its implementation. A significant finding is that the modeling and transmission of new behaviors to the company's staff, which was one of the project team responsibilities, had a rather successful implementation. Most interestingly, one may highlight that these efforts were not a result of a systematic approach, which in turn led to insufficient update of the staff on the progress of the project. As an additional note, even the individuals with the most extensive involvement in the project did not have a clear view of the strategies that the company asked them to implement.

\section{Empowering others to act on the vision}

The research results indicated an agreement in the interviewees' opinions with respect to the level of involvement of people in the project. In particular, the research identi-

ISSN: 07 I8-2724. (http://www.jotmi.org)

Journal of Technology Management \& Innovation (c) Universidad Alberto Hurtado, Facultad de Economía y Negocios. 


\begin{tabular}{|c|c|c|c|}
\hline & $\begin{array}{l}\text { Kotter's eight steps of } \\
\text { transformation }\end{array}$ & Validation Basis & Deviations \\
\hline 1 & $\begin{array}{l}\text { Establishing a sense of } \\
\text { urgency }\end{array}$ & $\begin{array}{l}\text { - IATA requirement } \\
\text { - Company’s viability }\end{array}$ & $\begin{array}{l}\text { - Hesitation to follow current industry } \\
\text { practices } \\
\text { - Slow developmental paces }\end{array}$ \\
\hline 2 & $\begin{array}{l}\text { Forming a Powerful Guid- } \\
\text { ing Coalition }\end{array}$ & $\begin{array}{l}\text { - Highly skilled project team } \\
\text { - Independency } \\
\text { - Flexibility }\end{array}$ & $\begin{array}{l}\text { - Top management not part of the project } \\
\text { team } \\
\text { - Delays in decision making due to compa- } \\
\text { ny's protocol }\end{array}$ \\
\hline 3 & Creating a Vision & $\begin{array}{l}\text { - Introduction of new e-ser- } \\
\text { vices in a very constrained } \\
\text { timeframe } \\
\text { - Necessity to improve the } \\
\text { company's market profile }\end{array}$ & $\begin{array}{l}\text { - Unclear strategies } \\
\text { - Inconsistent communication between } \\
\text { different groups }\end{array}$ \\
\hline 4 & $\begin{array}{l}\text { Communicating the } \\
\text { Vision }\end{array}$ & $\begin{array}{l}\text { - Company communicated } \\
\text { and disseminated project } \\
\text { related information } \\
\text { - Project team modeled and } \\
\text { transmitted new behavior to } \\
\text { staff }\end{array}$ & $\begin{array}{l}\text { - Efforts were not facilitated in a systematic } \\
\text { fashion } \\
\text { - Unclear view of the strategies to be imple- } \\
\text { mented }\end{array}$ \\
\hline 5 & $\begin{array}{l}\text { Empowering Others to } \\
\text { Act on the Vision }\end{array}$ & $\begin{array}{l}\text { - Progressive participation of } \\
\text { more staff } \\
\text { - Permission to lead and run } \\
\text { sub-projects }\end{array}$ & $\begin{array}{l}\text { - Staff reluctance and resistance to the actu- } \\
\text { al implementation of changes } \\
\text { - Financial issues (allocation of budget, } \\
\text { etc.) } \\
\text { - Delays caused by the company's bureau- } \\
\text { cracy (ineffective decision making pro- } \\
\text { cess). } \\
\text { - Problematic support by the top manage- } \\
\text { ment, enforced control and mitigation risk } \\
\text { by the project team }\end{array}$ \\
\hline 6 & $\begin{array}{l}\text { Planning for and Creating } \\
\text { Short-Term Wins }\end{array}$ & (not validated) & $\begin{array}{l}\text { - Lack of strategic planning short-term } \\
\text { goals and wins } \\
\text { - Staff morale not boosted in necessary } \\
\text { levels } \\
\text { - Absence of reward system }\end{array}$ \\
\hline 7 & $\begin{array}{l}\text { Consolidating Improve- } \\
\text { ments and Producing Still } \\
\text { More Change }\end{array}$ & $\begin{array}{l}\text { Realization of: } \\
\text { - Importance } \\
\text { - Reliability requirements } \\
\text { - Necessity for continuous } \\
\text { improvement }\end{array}$ & $\begin{array}{l}\text { - Absence of coordination by the company } \\
\text { to bring groups, teams and departments } \\
\text { together }\end{array}$ \\
\hline 8 & $\begin{array}{l}\text { Institutionalizing New } \\
\text { Approaches }\end{array}$ & $\begin{array}{l}\text { - Realization for deeper } \\
\text { changes }\end{array}$ & $\begin{array}{l}\text { - Insufficient momentum for the improve- } \\
\text { ment of the organization in a large scale }\end{array}$ \\
\hline
\end{tabular}

Table I Summary of research findings. Validated characteristics of each phase and observed deviations). 
fied that progressively more staff participated in the different tasks, as well as granted permission to lead and run sub-projects which were necessary for the support of the change process. Nevertheless, a significant problem faced in some cases was the staff reluctance and resistance to the actual implementation of changes that had to do mainly with new work conditions and responsibilities. Other obstacles included financial issues (allocation of budget, etc) and delays caused by the company's bureaucracy (ineffective decision making process). The interviewees also reported that due to the problematic support by the company's top management the project team had to carry out the control and mitigation of the project risks.

\section{Planning for and creating short-term wins}

Contradictory results characterize this phase, in terms of the diverse responses received by the interview participants. In practice, this exhibited the lack of strategic planning of short-term goals and wins during the implementation of the project. Therefore, one may recognize that the staff morale was not by any means boosted in the necessary levels, such that to cope with the extremely time pressuring situation and the organizational constraints and difficulties met. The planned company's privatization had affected the staff's morale and behaviors. Also, most of the staff involved in the research commented that the absence of any reward system affected negatively the change process.

\section{Consolidating improvements and producing still more change}

Based on the interview results, the implementation of the new e-services did assist the staff to realize the importance and the criticality of the project. As identified, this new system required a solid process capable of providing continuous improvements to accommodate the future demands. Another finding was that the company had not coordinated any efforts to bring groups, teams and departments together in order to spread, reinforce and enhance these changes.

\section{Institutionalizing new approaches}

The interview participants argued that a change in the organizational culture was a straightforward issue, which nevertheless required deeper changes due to the company's fundamental problems. The initiation of the changes emerged from the project requirements, but when taking closer look this is not sufficient to generate the momentum to improve the organization in a large scale. As indicated, a variety of reasons may have contributed to that, such as financial difficulties, technical problems, incompetent staff, problematic organizational culture, government interference and other issues.

\section{Conclusions}

The aim of this study was to examine and assess the effectiveness IT migration project in a state-owned airline, with respect to the phased change process proposed by Kotter (1995). The research questioned the validity and the extent of deviations in these eight phases through the critical analysis of interviews from the staff that had key roles and responsibilities in this project. The results obtained have indicated that in general there is an agreement with the characteristics of each phase; however, a closer look is necessary to distinguish some peculiar findings. In particular, despite the top management's commitment to migrate to new electronic services (selection of outsourcing solution, built-up of a highly skilled project team, project support), there were issues that obstructed and slowed down the process.

One of the factors that allowed the successful completion of this migration project, as recognized in the research, was the commitment of the project team, in terms of project leadership (guidance, control, risk management). Project team had to face the different challenges faced with respect to the organizational change that had to take place in this state owned company, just right from the early start of the project to the final launch of the new electronic services. Thus, one may consider that a significant degree of this success has to be attributed to staff improvisation, rather than the company's (top management) strategic efforts (lack of systematic and efficient reward system, absence of incentives for morale boost, etc). An additional finding was that although everyone was aware about the criticality of the situation, the top management did not direct or coordinate the update and training of the staff involved in the project, in terms of modeling new behaviors for transitioning to a new organizational culture. Unofficially, the project team has assigned to carry on this responsibility, in addition to their education duties. Every organization that goes through change gets into a transition period of non-smooth operation until the staff becomes accustomed with the new products and acquires new knowledge from using them. Therefore, trained and educated staff that knows more can do more, when management enables them with the right resources and strategies (Conner at al., 1992).

Based on the results, the participants changed their perspective about customer services and the competitiveness of the airline, which enabled them not only to change their own viewpoints, but also to assess the general performance of the company. This fact provides a clear indication of a transformative learning process; a critical reflection on the current knowledge, attitudes and beliefs that put new and current practices into a new perspective (Mezirow, 1981; Mezirow 1998). However, these reflection skills do not seem to be widespread since the company staff (from top to bot-

ISSN: 07 I8-2724. (http://www.jotmi.org)

Journal of Technology Management \& Innovation (c) Universidad Alberto Hurtado, Facultad de Economía y Negocios. 
tom) never initiated any action to commence critical reflection in light of the new developments. This in turn, is a drawback for any company, even for those with highly skilled staff, since the organizational culture influences the long-term economic performance (Kotter and Heskett, 20l I), which can be achieved only through an inclusive a holistic innovation approach and plan.

In summary, the introduction of new electronic systems, along with the change process that followed, was in line with the phases proposed by Kotter change management approach. Nevertheless, this was not a result of a well-developed strategic planning by the company's management, but mostly the commitment and personal interest of the project team that was responsible for the project implementation. The critical (negative) factor of bureaucracy, which is a defining element of many state-owned organizations throughout the world, influenced in a great extent the outcome, and it had an impact on organizational structure and decision making functions.

Further research on state-owned airlines in various regions and countries of the world could include an ethnographic study, as well as a detailed examination of the employees' working lives, attitudes and skills. This set of studies may provide an insight to the role of the staff and the project team during the development, implementation and transition process of a novel IT migration project. Adopting a 'census approach' would also be beneficial since that way it would be possible to identify the different levels of behavior, understanding and attitudes towards innovation, among the entire staff.

\section{References}

ALVESSON, M., Sveningsson, S. (2008). Changing Organizational Culture - Cultural Change Work in Progress, Routledge, Taylor and Francis Group, New York, USA.

BATHELEMY,J. (200I).The Hidden Costs of IT Outsourcing, MIT Sloan Management Review, 42(3), 60-ᄀ69.

BELOBABA, P., Fiig, T., Isler, K., Hopperstad, C. (2010). Optimization of Mixed Fare Structures, Journal of Revenue and Pricing Management, 9(I-2), I52-I 70.

BENNETTS, C. (2002). Traditional Mentor Relationships, Intimacy and Emotional Intelligence, Qualitative Studies in Education, I5(2), I55-I70.

BOSHOFF, K. (2005). Towards Facilitating Change in Service Delivery: An Illustrative Example, Australian Occupational Therapy Journal, 52(2), I49-I59.

BOVEY,W.H., Hede, A. (200I). Resistance to Organizational Change: The Role of Cognitive and Affective Processes, Leadership and Organization Development Journal, 22(8), 372-382.

CONLE, C. (2000). Narrative Inquiry: Research Tool and Medium for Professional Development, European Journal of Teacher Education, 23(I), 49-63.

CONNER, D., Branner, W., Kiefer, C., Mellander, K. (1992). Five Views of Change, Training and Development, 34-37.

COUTU, D.L. (2002). How Resilience Works, Harvard Business Review, 80, 46-55.

CUMMINGS, T., Worley, C. (2008). Organization Development and Change, 9th ed., South-Western College Publishing, Ohio, USA.

DOGANIS, R. (200I). The Airline Business in the 2 Ist Century, Routledge, London, UK.

GANTZ, J. (1990). Outsourcing: threat or salvation?, Networking Management, I0(90), 25-40.

GOFFEE, R., Jones, G. (2003). The Character of a Corporation - How Your Company's Culture Can Make or Break Your Business, 2nd ed., Profile Books Ltd, New York, USA.

JACKSON, D. (2000). Becoming Dynamic. Creating and Sustaining the Dynamic Organisation, Macmillan, London, UK.

ISSN: 07I 8-2724. (http://www.jotmi.org) 
KENNEDY, D. (2000). Acceptance. Developing Support for Change, Berrett-Koehler Communications, San Francisco, USA.

KOTTER, J.P. (1995). Leading Change: Why Transformation Efforts Fail, Harvard Business Review, 73(2), 59-67.

KOTTER, J.P., Heskett, J.L. (20II). Corporate Culture and Performance, Repr. Ed., Free Press, New York, USA.

LEE, S.K.J., Yu, K. (2004). Corporate Culture and Organizational Performance, Journal of Managerial Psychology, 19(4), 340-359.

LONGENECKER, C.O., Fink, L.S. (200I). Improving Management and Performance in Rapidly Changing Organizations, Journal of Management Development, 20(I), 7-I8.

McDONALD, M. (2009a). Technology standards don't stifle differentiation, proponents insist.

http://atwonline.com/it-distribution/article/technology-standards-dont-stifle-differentiation-proponents-insist-0309-0 (Accessed 20 August 2012)

McDONALD, M. (2009b). Do technology standards make sense for airlines' attempts to differentiate?

http://atwonline.com/it-distribution/news/do-technologystandards-make-sense-airlines-attempts-differentiate-0309 (Accessed 20 August 2012)

McLAUGHIN, S. (2009). The Imperatives of e-business: Case Study of a Failed Project, Journal of Business Strategy, 30(I), 40-49.

MEZIROW, J. ( I98I).A Critical Theory of Adult Learning and Education, Adult Education, 32(I), 3-24.

MEZIROW, J. ( 1998). On Critical Reflection,Adult Education Quarterly, 48(3), 185-198.

SENGUPTA, K., Zviran, M. (1997). Measuring User Satisfaction in the Outsourcing Environment, IEEE Transactions on Engineering Management, 44(4), 4I4-42I.

SIMPSON, S., Cacioppe, R. (200I). Unwritten Ground Rules: Transforming Organization Culture to Achieve Key Business Objectives and Outstanding Customer Service, Leadership and Organization Development Journal, 22(8), 394-40I.

SINGH, J., Singh, H. (20I2). Continuous Improvement Approach: State-of-art Review and Future Implications, International Journal of Lean Six Sigma, 3(2), 88- I I I.
SMITH, I. (2005). Continuing Professional Development and Workplace Learning II - Managing the "people" Side of Organisational Change, Library Management, 26(3).

STEINBURG, C. (1992). Taking Charge of Change, Training and Development, 46(3), 26-32.

STRONG, B., Davenport, T. H., Prusak, L. (2008). Organizational Governance of Knowledge and Learning, Knowledge Processing Management, I5, I50-I57.

VIOLANTE, F. (2008). Speech: IT Trends in Air Transport http://www.sita.aero/content/speech-it-trends-air-transport-francesco-violante-ceo-sita-0 (Accessed I 5 July 20I2).

WASHINGTON, M., Hacker, M. (2005). Why Change Fails: Knowledge counts, Leadership and Organization Development Journal, 26(5), 400-4II. 